Ansell N and Young L (2004) 'Enabling households to support successful migration of AIDS orphans in southern Africa' AIDS Care 16(I) 3-10

Enabling households to support successful migration of AIDS orphans in southern Africa

Dr Nicola Ansell

Lecturer in Human Geography

and

Dr Lorraine Young

Lecturer in Human Geography

Department of Geography and Earth Sciences

Brunel University

Kingston Lane

Uxbridge

UB8 3PH

Telephone: 01895203215

Fax: 01895203217

Email: nicola.ansell@brunel.ac.uk; lorraine.young@brunel.ac.uk 


\section{Enabling households to support successful migration of AIDS orphans in southern}

\section{Africa}

\section{Abstract}

Most southern African orphans are cared for by extended families but the implications of the spatial dispersal of such families are seldom recognised: orphans often have to migrate to new homes and communities. This paper, based on qualitative research conducted with children and guardians in urban and rural Lesotho and Malawi, examines orphans' migration experiences in order to assess how successful migration might best be supported.

Most children found migration traumatic in the short term, but over time many settled into new environments. Although much AIDS policy in southern Africa stresses the role of communities, the burden of care lay with extended family households. Failed migrations, which resulted in renewed migration and trauma, were attributable to one of two household-level causes: orphans feeling ill-treated in their new families or changes in guardians' circumstances.

Policy interventions to reduce disruption and trauma for young AIDS migrants should aim at facilitating sustainable arrangements by enabling suitable households to provide care. Reducing the economic costs of caring for children, particularly school-related costs, would: allow children to stay with those relatives (e.g. grandparents) best able to meet their nonmaterial needs; reduce resentment of foster children in impoverished households; and diminish the need for multiple migrations. 
Enabling households to support successful migration of AIDS orphans in southern Africa

\section{Background}

The number of children orphaned by AIDS in southern Africa is large and growing. In Malawi, where the epidemic is long established, $17.5 \%$ of children aged $0-14$ are orphans (USAID/UNICEF/UNAIDS 2002). Of 937,000 orphans, 468,000 have lost parents to AIDS (ibid). In Lesotho, where the onset of the epidemic has been more recent but more acute, orphans similarly account for $17 \%$ of children (ibid). Here estimated numbers have increased rapidly, from 76,000 in 2000 (Hunter \& Williamson 2000) to 137,000 in 2001, AIDS accounting for more than half the total (USAID/UNICEF/UNAIDS 2002).

It is widely recognised that most southern African orphans are cared for by their extended families (Barnett \& Whiteside 1999). However, across southern Africa, families are commonly spatially dispersed: a legacy of the region's history of labour migration (Murray 1981). This dispersal has implications for the care of orphans by their kin, as those best placed to care for AIDS-affected children are often resident at considerable distance from the children's original home. Many orphans therefore engage in migration in order to receive care and support. Despite this, policy responses to the needs of AIDS orphans have taken little, if any, account of the impacts of such migration.

Policy responses to HIVIAIDS favour fostering of orphans within the extended family, and recognise that relatives who accept orphans are often elderly and/or poor, and therefore in need of support. Significantly, 'family' is usually allied with 'community', and policies concerning orphans (e.g. Zimbabwe's National Policy on the Care and Protection of Orphans (UNAIDS/UNICEF 1999), Lesotho's National AIDS Strategic Plan (Government of Lesotho 2000) and Malawi's draft National Policy on Orphans and Vulnerable Children (Republic of Malawi 2001)) stress the necessity of 'community-based care'. UNICEF's report on programming for families and children affected by HIVIAIDS in Lesotho declares that 'it is 
assumed that community based approaches are the only viable and sustainable alternative for providing care and protection for children made vulnerable by the HIVIAIDS epidemic' (UNICEF 1999).

'Community-based care' is an ambiguous term, used in several senses, including: care in the community (i.e. not in institutions); care organised at the community level (for example, coordination of service provision through Community AIDS Committees (National Task Force on Orphans in Malawi 1996)); and care by the community (mobilisation of individuals/groups to donate time and money to supporting orphans). In all these senses it is assumed that there is a readily identifiable static community to which orphaned children and their guardians belong. Although migration has, on occasion, been noted as a possible obstacle to successful community responses (UNAIDS 1999), no attention has been given to the fact that many orphans are newcomers to the communities in which they reside. As will be demonstrated, migration by orphans renders problematic their relationships with communities, and demands policy responses directed at enabling households to support successful migration. ${ }^{1}$ To assess how migration might best be supported, this paper considers the difficulties young migrants face, the support available to them, and the reasons why some migrations fail.

\section{Methods}

Research was conducted in urban and rural communities in Lesotho and Malawi. In Lesotho the research took place in the capital city, Maseru, and in Tlali, a village in the foothills of the Maluti Mountains, some $100 \mathrm{~km}$ from Maseru. In Malawi, the research locations were a highdensity suburb of Blantyre, the largest city, and Mpando, a village in tea-growing Thyolo District, $100 \mathrm{~km}$ south of Blantyre. Questionnaires were completed by 822 children aged 10-17 attending local schools, in order to identify those who had migrated and experienced parental sickness or death, or whose households had received incoming children in similar

\footnotetext{
1 This paper focuses on household/community level responses to children's migration. Possibilities for empowering individual children are discussed elsewhere (Young \& Ansell 2002b).
} 
circumstances. $^{2}$ Focus groups were conducted with 226 such children and a further 70 who were out-of-school, living on the streets or in institutions. Sixty-five children were selected to draw storyboards depicting personal migration experiences, which acted as prompts to elicit the detailed narratives which provide the main source for this paper. Interviews were also conducted with 40 guardians who had received children from elsewhere, to ascertain their perspectives on the children's migration experiences.

\section{Results}

Migrations undertaken by AIDS-affected children take many forms and are often highly complex. Although some migrations are directly prompted by AIDS, in many instances the causal chain between illness/death of a relative and a child's migration is not straightforward. Some migrations are undertaken with a surviving parent, while in other cases children move alone or with siblings. The effect of AIDS may even be that children return to live with parents after residing with other relatives. Thabang, ${ }^{3}$ in Lesotho, for instance, went to live with his father for the first time, to care for him during his terminal illness. Peter, in Malawi, had been living with his grandmother, but when his father died, his grandmother lost her son's financial support and could no longer care for Peter, so he moved to live with his mother.

\section{Difficulties for young migrants}

Migration experiences are both complex and varied and their impacts on children differ. Most children find migration traumatic in the short term, experiencing a range of difficulties related to fitting into 'new' families and 'new' communities (Young \& Ansell 2002a).

When households adopt children through a sense of obligation, as is usually the case with AIDS orphans (Urassa et al. 1997), they are often treated differently from the family's

\footnotetext{
${ }^{2}$ Very few children are willing to attribute deaths in their families directly to AIDS, hence those whose parents had been ill or died from illnesses commonly associated with AIDS were included. Equally, the immediate cause of migration was often other than parental sickness or death, but AIDS was commonly the underlying reason.

${ }^{3}$ Pseudonyms are used to protect confidentiality.
} 
'biological' children, particularly if resources are scarce. Migrant children report being given different food, inadequately provided with clothing, beaten and overworked.

It was hard to stay with my uncle as he was just a cruel man. He had many children, and he favoured them when we shared food and gifts, and I was overworked like a slave. The other children didn't do any work, just me. (Brenda's storyboard, Mpando)

Children joining new families may also experience jealousy and rivalry from the household's resident children. Their 'new' siblings may be reluctant to share either material resources, or the emotional attention required when coming to terms with parental death.

Because of AIDS-related poverty, some young migrants are expected to work for their keep in their new households: a situation that places them as unequal members of the new family. Other children are sent to engage in wage labour away from home to support younger children. This both removes them from their family and causes them to drop out of school.

Migrating children also have to fit into new communities that may differ significantly from those they move from. Children migrating from urban to rural environments find it particularly difficult to adapt to agricultural chores; principally herding in Lesotho and field work in Malawi. Not only are the new tasks physically challenging, but rural children are seldom sympathetic to their plight.

It's painful because we go and herd in the rain. We aren't given any blankets because we are told we haven't bought any. (Tlali out-of-school boys' focus group)

Children moving over long distances experience social difficulties, arising from the need to develop new social contacts and missing their friends. The trauma of losing a parent makes integration more difficult and guardians noted that newcomers were often withdrawn and found it difficult to engage with other children.

The children were very sad after their parents' deaths, and lonely, and I could tell they were not at peace. (Tlali aunt) 
The increasingly assumed relationship between orphanhood and AIDS exacerbates problems of integration into community life (Webb 1997). This was particularly the case in Lesotho where AIDS is more recent, less widespread and carries greater stigma.

Migration between communities is often associated with dropping out of school, particularly for those who return to live with rural grandparents. Those who move to new schools may find that they must follow a different curriculum, or even learn in a new language.

I had a bad experience coming here because in Zimbabwe I was very clever as we learnt in our own language, but when I came to Malawi it was hard for me to learn Chichewa, so I failed in Chichewa, and that's why I'm in Standard 6. If I could count the classes from being in Zimbabwe I'd be in Form 2 by now. (McDonald's storyboard, Blantyre)

Many of the difficulties young migrants face, such as dropping out of school, having to work and resentment by household members, relate to the costs of providing for orphans when resources are scarce. Furthermore, in situations of poverty, economic capacity is often prioritised in the selection of guardians: hence receiving households may not be those best equipped to cater for children's non-material needs.

\section{Support for young migrants}

While migration creates initial difficulties for most children, in time these difficulties are usually overcome. Children arriving to stay with relatives gain their primary support from within the receiving household. Guardians talked of how children were helped to 'fit in' to their new home and environment:

I was comforting them by trying to get the food they liked, even though we didn't eat it here, but this helped them to be comfortable in this place, and get used to having new parents. (Thyolo uncle)

In order to provide economic support, some guardians, particularly grandmothers, had to access new resources by, for example, taking employment or starting a business. Although very aware of children's need for support in the form of food, clothing and where possible attendance at school, guardians were, however, often less aware of young people's psychosocial needs. This is of particular importance where children have not only experienced 
the prolonged sickness and death of family members, but have also been removed from previous social networks and familiar surroundings (Munthali \& Ali 2000).

Children receive some support from outside the immediate household, mainly from other family members, both local and non-local. Despite the policy stress on the role of communities, in practice communities were found to have minimal involvement in caring for incoming children. Very few children or guardians reported receiving any formal or informal assistance from nonrelated community members, although some in the cities received assistance from NGOs. Some schools also endeavoured to facilitate the incorporation of incoming children by, for instance, placing migrant children in separate classes which were able to address their particular needs, and allowing them to continue to wear the uniforms of their previous schools on a temporary basis.

Over time, most children settled into their new homes, being accepted by both adults and children. Ruth reported of her cousin who moved to live with her family after his parents died:

After a while he became used to ... living with us ... We then became friends with him. My sister and I were then closer to him than we were to our other brothers. (Ruth's storyboard, Blantyre)

\section{Failed migrations}

Children who settle happily into new homes clearly represent 'success stories' of migration. Of the 65 children who drew storyboards illustrating migration experiences, however, 22 described undertaking more than one migration following the death of a parent or other guardian. Some had migrated as many as five times. While multiple migrations are not always problematic, they do suggest that many children undergo repeated disruption and trauma in their lives, and also signal the failure of the initial migration. Analysing the causes of repeat migrations may both inform ways of reducing the repeated disruption to children and suggest possibilities for making children's migration more successful. 
Children's storyboards revealed two basic reasons why migrations failed, resulting in renewed migration and trauma, both relating to mainly household-level factors. In some instances children felt so unhappy in their new homes that they decided to leave; in other cases children were required to leave because of changed circumstances.

A minority of migrant children failed to settle. Whereas the initial decisions about where children should live following parental death were almost invariably taken by adults, often on the basis of short-term economic considerations, some children felt so discriminated against or abused in their new household that they took the decision to leave. Some felt their guardians cared little about them, and that this was reflected in an unwillingness to spend any money on them. [My cousin] came to stay with us because his aunt was ill-treating him, because when his uncle gave her money to buy the children shoes, she didn't buy them. (Lumbani's storyboard, Blantyre)

In other cases, children were made to work harder than they considered reasonable, or to engage in work during school hours that deprived them of their education. Resistance to such work was often met with harsh discipline, which fuelled their motivation to leave the household, even if there was nowhere to go but the streets. Most Blantyre street children described similar reasons for leaving home:

When my parents died I went to live with my grandmother who was harsh to me and made me do most of the work alone ... I ran away and took the bus to Blantyre. (McBride's storyboard, Blantyre streetkid)

Although some children felt mistreated by grandparents, who often depended on them for physical labour, most stories of ill-treatment related to other relatives: aunts, uncles, and especially stepparents. This may reflect the fact that these relatives often have dependent children of their own, who they tend to favour. After the death of his mother, Edison 's father remarried and took his son to his new wife's home in Dedza.

I didn't like going there as I couldn't go on with school, because I left at 3am to go to the fields and I got back at 11am so school was already gone ... I loved my stepmother but she didn't love me back and would beat me often and insult me for no reason. (Edison's storyboard, Blantyre streetkid) 
Most repeat migrations were not, however, instigated by children themselves, but reflected changes in circumstances which required them to move. Usually the prompt was a change in their guardian's situation. Guardians sometimes became sick and unable to offer continued (adequate) care, or even died. This is particularly common as AIDS clusters in families, and because many children are cared for by elderly grandparents. Liau, for instance, had moved to live with his grandparents when his mother died.

My grandmother got sick and moved to her daughter's place ... and I stayed behind with her husband ... He'd leave the house and take the key and go drinking, so l'd come back from school and couldn't go inside to eat, and I had to wait outside and he came back very late. So I moved back to Tlali to live with my older brother and sister. (Liau's storyboard, Tlali)

Other guardians (re)married, and were unable or unwilling to take children into their new marital homes. Muliwo had moved four times with his mother after his father's death, then:

When we were in Blantyre, my mother remarried, so they had to send me back to my grandmother's place in Thyolo. (Muliwo's storyboard, Mpando)

Migration was also prompted when a guardian became unemployed, either because the home was tied to the job, or because there were no longer adequate economic resources to provide for the child. Lillian had felt mistreated by her stepmother following her mother's death, and had moved to live with a grandmother who also made her work hard and miss school. Her uncle then took her to live in Blantyre where she was happy, but when he lost his job she had to return to her father and stepmother.

The death of a guardian's spouse may also deprive households of the resources (including sometimes their home) needed to care for their charges. When Sello's aunt fell out with her inlaws, following her husband's death, he had to leave their Maseru home.

Circumstances may also change in other households, prompting a move. If a relative develops a need for assistance (because they grow old, lose their existing help, or become sick), an orphan might be sent to help them. Mary had stayed with her aunt in Blantyre for two years 
following her mother's death, but was taken back to her original village by her grandmother to do housework.

Equally, if a relative resident elsewhere perceives that an orphan's needs are unmet, they may take the child to live with them. It was common (particularly in Lesotho) for uncles to take children in order to send them to school.

I moved from Quthing to Maseru to attend school. I travelled alone to stay with my uncle. It felt painful, but I had no choice as I wanted to attend school. My brothers were not financially able to send me to school. (Masaoli's storyboard, Maseru)

There are some changes of circumstance which are entirely outside the control of the individuals involved. For example, when Richard's mother died, he left Malawi and went with his sister to Mozambique. The arrival of war in the vicinity prompted his subsequent return to his grandmother's home in Mpando.

Failed migrations occur where children are seriously unhappy in their new homes, or where situations change. On occasion, given that grandparents are old and many adults have AIDS, this is unavoidable. In other cases, underlying reasons may be identified: sometimes (often for economic reasons) orphans are taken into households that are either not equipped or not motivated to provide the care needed. Even if children are treated well in the first instance, when situations change some guardians quickly renege on commitments. Others find that they are ill-resourced to continue to support their charges.

\section{Policy implications}

The research reported here suggests that it is important that if children migrate when their parents die, they should move to a situation that is sustainable. Arrangements for the care of orphans need to take into account a range of factors, not least guardians' commitment to caring for children. Where guardians are selected for short-term economic viability they may prove inadequate care providers, or unwilling to continue as guardians in the event of changed 
circumstances. It is thus imperative that policies support those guardians best able to offer sustainable long-term homes.

It is noteworthy that where grandparents take in orphans, the arrangement is three times more likely to last than if children enter the homes of aunts and uncles. However, grandparents are sometimes unable to accept children on account of poverty, and where children choose to leave grandparents' homes it is usually poverty-inspired. The most effective means of supporting the care of orphans by grandparents (or other committed guardians) would be to reduce the costs of accepting orphans, and provide assistance in accessing the necessary resources. This would not only enable the most suitable households to care for children, but would also reduce the resentment of orphans in receiving households. It would make children's experience of migration to a new home more agreeable, and reduce the need for onward migration, either due to children's unhappiness, or to the impoverishment of guardians.

There are a number of means by which the costs of accepting orphans could be reduced, some of which are already being implemented. The introduction of free primary education in Malawi may explain why fewer children migrate to attend school here than in Lesotho (where fees are now being eliminated on a rolling basis). There are also many projects designed to support income-generating activities among guardians.

In both Lesotho and Malawi, orphaned children were generally considered the responsibility of their kin, and not the wider community. Children who ceased to be able to access support from one relative were highly unlikely to look to unrelated community members for assistance, but instead left the community, either to stay with relatives elsewhere, or to seek their survival on the streets. This is not to suggest communities can have no role in the support of orphans, for example in facilitating family care of orphans through income-generating activities. However, policies must recognise the distinct roles played by families and communities in highly migrant societies. 


\section{Acknowledgements}

This research was funded by the UK Department for International Development (DFID). DFID supports policies, programmes and projects to promote international development. DFID provided funds for this study as part of that objective but the views and opinions expressed are those of the authors alone.

\section{References}

BARNETT, T., \& WHITESIDE, A. (1999, 5-8 September 1999). HIVIAIDS in Africa: implications for 'development' and major policy implications. Paper presented at the SCUSA Inter-University Colloquium, UEA, Norwich.

GOVERNMENT OF LESOTHO. (2000). National AIDS strategic plan 2000/2001-2003/2004: a three-year rolling plan for the national response to the HIVIAIDS epidemic in Lesotho. Lesotho: Government of Lesotho.

HUNTER, S., \& WILLIAMSON, J. (2000). Children on the brink: executive summary: updated estimates and recommendations for intervention. Washington, DC: USAID.

MUNTHALI, A. C., \& ALI, S. (2000). Adaptive strategies and coping mechanisms: the effect of HIVIAIDS on the informal social security system in Malawi. Lilongwe: Government of Malawi, National Economic Council.

MURRAY, C. (1981). Families divided: the impact of migrant labour in Lesotho. Cambridge: Cambridge University Press.

NATIONAL TASK FORCE ON ORPHANS IN MALAWI. (1996). National orphan care programme 1996-1998. Lilongwe: Ministry of Women and Children Affairs, Community Development and Social Welfare.

REPUBLIC OF MALAWI. (2001). National policy on orphans and vulnerable children: support an orphan today for a better tomorrow (Revised Draft ). Lilongwe: Ministry of Gender, Youth and Community Services.

UNAIDS. (1999). A review of household and community responses to the HIVIAIDS epidemic in the rural areas of southern Africa. Geneva: UNAIDS. 
UNAIDS/UNICEF. (1999). Children orphaned by AIDS: front-line responses from eastern and southern Africa.

UNICEF. (1999). Building systems of protection for children affected by HIVIAIDS in Lesotho: report of an assessment of programming in Lesotho for families and children affected by HIVIAIDS (Draft): UNICEF.

URASSA, M., BOERMA, J. T., NG'WESHEMI, J., ISINGO, R., SCHAPINK, D., \& KUMOGOLA, Y. (1997). Orphanhood, child fostering and the AIDS epidemic in rural Tanzania. Health Transition Review, 7(Supplement 2), 141-153.

USAID/UNICEF/UNAIDS. (2002). Children on the brink 2002: a joint report on orphan estimates and program strategies. USAID/UNICEF/UNAIDS.

WEBB, D. (1997). HIV and AIDS in Africa. London: Pluto.

YOUNG, L., \& ANSELL, N. (2002a). Fragmenting households: children's migration as a response to HIVIAIDS in Malawi and Lesotho. Submitted manuscript.

YOUNG, L., \& ANSELL, N. (2002b). Young AIDS migrants in southern Africa: policy implications for empowering children. AIDS Care (forthcoming). 